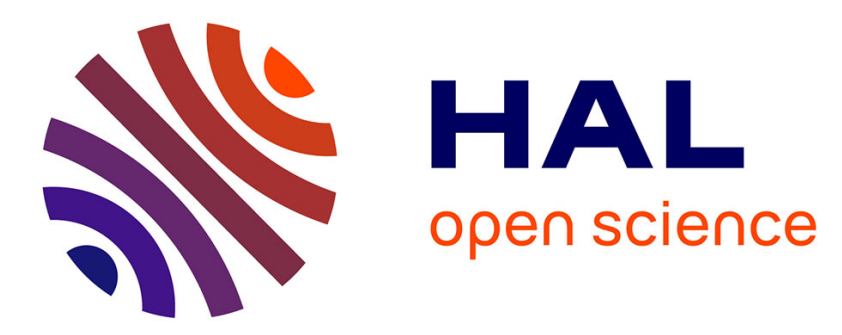

\title{
Damage tolerance assessment of the interface strength gradation in thermoplastic composites
}

\author{
Luigi Sorrentino, Fabrizio Sarasini, Jacopo Tirillo, Fabienne Touchard, \\ Laurence Chocinski-Arnault, David Mellier, Pietro Russo
}

\section{To cite this version:}

Luigi Sorrentino, Fabrizio Sarasini, Jacopo Tirillo, Fabienne Touchard, Laurence Chocinski-Arnault, et al.. Damage tolerance assessment of the interface strength gradation in thermoplastic composites. Composites Part B: Engineering, 2017, 113, pp.111-122. 10.1016/j.compositesb.2017.01.014 . hal02336918

\section{HAL Id: hal-02336918 \\ https://hal.science/hal-02336918}

Submitted on 19 Jul 2020

HAL is a multi-disciplinary open access archive for the deposit and dissemination of scientific research documents, whether they are published or not. The documents may come from teaching and research institutions in France or abroad, or from public or private research centers.
L'archive ouverte pluridisciplinaire HAL, est destinée au dépôt et à la diffusion de documents scientifiques de niveau recherche, publiés ou non, émanant des établissements d'enseignement et de recherche français ou étrangers, des laboratoires publics ou privés. 


\section{Damage tolerance assessment of the interface strength gradation in thermoplastic composites}

Article in Composites Part B Engineering · January 2017

DOI: 10.1016/j.compositesb.2017.01.014

CITATIONS

0

7 authors, including:

\section{Fabrizio Sarasini}

Sapienza University of Rome

106 PUBLICATIONS 1,256 CITATIONS

SEE PROFILE

\section{David Mellier}

French National Centre for Scientific Research 17 PUBLICATIONS 28 CITATIONS

SEE PROFILE

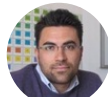

Jacopo Tirillò

Sapienza University of Rome

64 PUBLICATIONS 459 CITATIONS

SEE PROFILE

\section{Pietro Russo}

Italian National Research Council

105 PUBLICATIONS 889 CITATIONS

SEE PROFILE

Some of the authors of this publication are also working on these related projects: 


\title{
Damage tolerance assessment of the interface strength gradation in thermoplastic composites
}

\author{
Luigi Sorrentino $^{\text {a, }}{ }^{*}$, Fabrizio Sarasini ${ }^{\mathrm{b}}$, Jacopo Tirillò ${ }^{\mathrm{b}}$, Fabienne Touchard ${ }^{\mathrm{c}}$, \\ Laurence Chocinski-Arnault ${ }^{\mathrm{c}}$, David Mellier ${ }^{\mathrm{c}}$, Pietro Russo ${ }^{\mathrm{a}}$ \\ a Institute for Polymers, Composites and Biomaterials (IPCB)-CNR, Piazzale Enrico Fermi 1, Località Granatello, 80055 Portici (NA), Italy \\ b Sapienza Università di Roma, Department of Chemical Engineering Materials Environment and UDR INSTM, via Eudossiana 18, 00184 Rome, Italy \\ ${ }^{\mathrm{c}}$ PPRIME Institute, CNRS-ISAE-ENSMA-University of Poitiers, 1 Av. Clement Ader, B.P. 40109, 86961 Futuroscope, France
}

\section{A R T I C L E I N F O}

\section{Article history:}

Received 16 November 2016

Received in revised form

22 December 2016

Accepted 8 January 2017

Available online 10 January 2017

\section{Keywords:}

IGIS composite design

Thermoplastic composites

Micro-computed tomography

Acoustic emission

\begin{abstract}
A B S T R A C T
The newly developed hybridization approach for thermoplastic composites, based on the gradation of the interlaminar interface strength (IGIS design), was used to prepare polypropylene/glass fibre composites by properly alternating layers of reinforcing fabric with compatibilized and not compatibilized polymeric films. Maleated polypropylene was used to improve the matrix/fibre interface strength. The flexural and low-velocity impact characterizations showed that the use of the coupling agent improved the quasi-static flexural properties through the strengthening of the matrix/fibre interface, but considerably lowered the low velocity impact resistance of the laminate. The use of the IGIS design, which grades the interface strength through the laminate thickness, enabled the fabrication of composites with a favourable combination of flexural properties and impact resistance and proved to be effective in better preserving the integrity of the fibres. The damage after impact has been assessed by means of microcomputed tomography, which elucidated the improving effect of the matrix hybridization on the impact resistance, and acoustic emission analysis, which allowed the identification of the mechanisms responsible for impact energy absorption. The role played by the matrix hybridization sequence was pointed out along with the effective role of IGIS design in the overall mechanical performance of laminates.
\end{abstract}

(c) 2017 Elsevier Ltd. All rights reserved.

\section{Introduction}

Thermoplastic composites (TPC) have gained increasing interest in various industrial fields (civil engineering, transportations, automotive industry, aeronautics to name a few) mainly due to a favourable combination of properties, including high stiffness to weight ratio, high damage tolerance, good chemical stability, low moisture absorption, high energy absorption capability, recyclability and rapid manufacturing with respect to thermosetting based composites [1,2] Although initially the application of TPCs was restricted to semi-structural components (for example front-end panels, spare wheel wells and door panels), fully structural applications are emerging such as crash boxes [3].

Among all thermoplastic composites, systems based on polypropylene (PP) and glass fibres have been widely investigated

\footnotetext{
* Corresponding author.

E-mail address: luigi.sorrentino@cnr.it (L. Sorrentino).
}

because both constituents and the resulting laminates have a very high performance/cost ratio and high specific properties [4-6]. Polypropylene is one of the most extensively used polymers in industrial applications due to its high chemical and wear resistance, easy processability, low cost and excellent specific mechanical properties. In the same fashion, glass fibres are characterized by a low cost, high tensile strength, high chemical resistance and insulating properties. The main drawbacks of glass fibres are the low elastic modulus (lower than carbon fibres), low fatigue resistance and a challenging adhesion with PP due to the very different polarity of the two species (polar molecular structure in the glass and non-polar in the polypropylene).

Since the static structural properties of a laminate are largely influenced by the interface strength between fibres and matrix, various strategies have been developed to improve the interfacial adhesion between PP and glass fibres. Successful results have been achieved by treating the surface of fibres to enhance the compatibility with non-polar species $[7]$ and by improving the polarity of 
the matrix by means of a suitable coupling agent [8]. Russo et al. [9] investigated the effect of the addition of a common coupling agent (polypropylene grafted with maleic anhydride, PP-g-MA) on the mechanical behaviour of laminates based on different grades of polypropylene and found that its use strongly increases the flexural strength of the composites.

Usually, composites based on very stiff fibres are characterized by low toughness and low impact absorbing capabilities. Such impact behaviour depends on many factors such as fibre type, reinforcement configuration, interface properties, laminate thickness, preform architecture and sequence lay-up. An appropriate optimization of these parameters increases the damage resistance and damage tolerance of laminates but only limited improvements can be obtained unless different methodologies are used. In this regard, the fibre hybridization approach, which mixes stiff with tough fibres in the same lamina or in different laminae to form interply or intraply laminates, respectively, has proved to be a very effective way to balance stiffness and toughness and improve the impact energy absorbing capability of composite laminate systems [10-14]. A drawback of the reinforcement hybridization is that the use of different fibres can make more complex the design of the laminate since further parameters should be considered. In particular, the different fibres have distinct thermal expansion coefficients, moisture absorption, matrix/fibre interface strengths, diameters (and hence impregnation conditions).

Recently a new approach (named IGIS from Interlaminar Graded Interface Strength) has been proposed that works on the hybridization of the matrix instead of the reinforcement [9,15-18]. This approach does not affect the reinforcement and does not increase the design parameters nor requires changes to the processing technology. It exploits the technology used for thermoplastic composites to hybridize the matrix instead of the reinforcement by alternating layers of compatibilized or not-compatibilized polymer with reinforcing fabrics. The analysis of the low velocity impact behaviour of IGIS composites based on PP and glass fibre fabrics has shown that a strong interface strength reduces the energy absorption capabilities of the laminate while the proper positioning of polymeric layers with a low fibre/matrix interface strength strongly improves the low velocity impact damage tolerance while keeping high the static mechanical response [15].

The impact behaviour strongly influences the potential application fields of laminated structures hence it is fundamental to understand how the composite structure responds to the application of impulsive and intense loads. In recent years, X-ray microcomputed tomography (micro-CT) has emerged as a nondestructive 3D visualization technique for material characterization [19]. It is based on measurement of the attenuation of X-ray photons. When incident photons pass through an object, their attenuation will depend on the physical density of the object. Contrast arises because different phases (and defects) have different levels of X-ray attenuation [20]. The studied object is rotated through $360^{\circ}$ while a series of high-resolution digital radiographs (projections) are acquired. Then, the recorded data are processed and converted into a stack of slices to reconstruct the 3D volume. This technique can be applied to a variety of problems in materials research as reviewed by Stock [21]. In the field of composite research, it is particularly adapted for studying the internal damage, including delamination and microcracking [22]. For example, micro-CT technique has been used for analysing failure mechanisms in 3D woven composites [19,23] or for studying damage evolution in open hole carbon fibre-reinforced laminates $[24,25]$. Concerning the characterization of impact damage, fewer studies have been reported and they all concerned thermoset composites. The impact damage due to a gas-gun-fired projectile in carbon/epoxy laminates has been analysed by Symons [26] and
Penumadu et al. [27]. The impact damage due to a laser shock in basalt-carbon/epoxy composites has been studied by Ferrante et al. [28]. Dunkers et al. studied the drop-weight impact damage in glass/epoxy composites [29], Fidan et al. in glass-aramid/polyester laminates [30], and Nash et al. in carbon/benzoxazine composites with a thermoplastic toughening interlayer [31].

After low-velocity impacts, an area of interest is the effect of damage on the mechanical properties of laminated composite structures, thus assessing what is generally known as damage tolerance. Post-impact strength measurements are usually carried out in compression and this represents also the only one standardized method (ASTM D7137), irrespective of the matrix type, being thermosetting or thermoplastic in nature [32-34]. Compression is critical for impact-damaged specimens because under this type of loading the strength reductions are the most severe [35-38]. In this study four point bending tests have been used as a post-impact evaluation tool, which were monitored by acoustic emission (AE) in an attempt to identify and discriminate the failure modes of the different configurations. AE is capable of detecting the dynamic processes associated to the degradation of structural integrity and therefore can be used to monitor in situ a structure during loading. AE has been applied on all classes of materials and a lot of specific mechanisms responsible for AE have been identified. In particular, in composite materials mechanisms such as fibre failure, debonding at fibre/matrix interface, plastic deformation and matrix cracks, delamination, friction between fibres and matrix have been detected. AE proved to be effective in detecting and discriminating these damage mechanisms in a variety of testing conditions, ranging from quasi-static [39-42], dynamic (fatigue) $[43,44]$ and post-impact ones $[28,45,46]$.

In this contribution, the impact damages induced on IGIS laminates after a low velocity impact have been analysed by means of microtomography and the damage tolerance of IGIS structures has been assessed by flexural tests monitored by acoustic emission technique.

\section{Experimental}

\subsection{Materials}

The polypropylene used was the MA712 grade supplied by Unipetrol - Czech Republic (MFI = 12 g/10 min; referred to as "N"). Polypropylene grafted with maleic anhydride, commercialized under the trade name Polybond 3200 (MFI = $115 \mathrm{~g} / 10 \mathrm{~min}, 1 \mathrm{wt} \%$ maleic anhydride; from Chemtura, Philadelphia - PA, USA) was used at $2.0 \%$ by weight as coupling agent to improve the fibre/ matrix interface. Compatibilized matrix has been referred to as " $\mathrm{C}$ ". Finally, a plain weave type glass woven fabric (E-glass fibres having density of $2.54 \mathrm{~g} / \mathrm{cm}^{3}$, functionalized by amino silane groups) with a specific mass of $204 \mathrm{~g} / \mathrm{m}^{2}$ has been used as reinforcing fabric.

\subsection{Sample preparation}

Films of neat or compatibilized polypropylene having a thickness equal to $35-40 \mu \mathrm{m}$ were prepared by using a film blowing extrusion line model Teach-Line E 20 T from Collin GmbH (Ebersberg, Germany). Composite laminates were produced by using the film stacking technique by means of a compression moulding machine (model P300P, Collin GmbH, Ebersberg, Germany). Twenty layers of polypropylene films and twenty of glass woven fabric were alternatively stacked according to the specific stacking sequence (Table 1) as schematized in Ref. [17] and heated according to opportune temperature and pressure profiles by using a laboratory press [9]. Samples consisting of 20 balanced fabric layers $0 /$ 90 , symmetrically arranged with respect to the middle plane of the 
Table 1

Coding of IGIS laminates and sequence of PP layers used to produce the composite $(\mathrm{N}=$ not compatibilized PP layer; $\mathrm{C}=$ compatibilized PP layer; $\mathrm{H}=\mathrm{IGIS}$ hybridized matrix sequence).

\begin{tabular}{ll}
\hline Sample & Polymeric Layer Sequence \\
\hline NEAT & $20 \mathrm{~N}$ \\
COMP & $20 \mathrm{C}$ \\
HNC & $10 \mathrm{~N} / 10 \mathrm{C}$ \\
HCN & $10 \mathrm{C} / 10 \mathrm{~N}$ \\
HNCN & $5 \mathrm{~N} / 10 \mathrm{C} / 5 \mathrm{~N}$ \\
HCNC & $5 \mathrm{C} / 10 \mathrm{~N} / 5 \mathrm{C}$ \\
HX & $2 \mathrm{C} / 5 \mathrm{~N} / 6 \mathrm{C} / 5 \mathrm{~N} / 2 \mathrm{C}$ \\
\hline
\end{tabular}

laminate $\left(\left[(0 / 90)_{10}\right]_{s}\right.$ configuration), were produced with a target thickness of $3.30 \mathrm{~mm}$ and a glass fibre content of $45 \%$ by volume. The volume percentages of fibre and matrix were evaluated according to the ASTM D 3171 and ASTM D792, respectively.

\subsection{Characterization techniques}

Optical analyses were performed in reflection mode by using a microscope (Z16 APO from Leica GmBH, Germany) to observe the damage modes after the four point bending test. The observed surface of samples was preliminarily treated with a wet fine sandpaper and then polished with a very fine polishing paste. Fibre wetting was investigated by analysing fractured surfaces with a field emission scanning electron microscope (model QUANTA200FEG from FEI - Eindhoven, The Nederlands). The examined surfaces were preliminarily coated with a thin layer of a goldpalladium alloy prior to SEM analysis.

Four-point bending tests have been performed on three specimens $(170 \mathrm{~mm} \times 60 \mathrm{~mm})$ for each configuration in accordance with ASTM D 6272. This unusual width has been chosen in order to be sure of accommodating the whole impact damaged area, thus minimizing the edge effects. The distance between the loading noses (the load span) was one half of the support span $(80 \mathrm{~mm})$. A cross-head speed of $2.5 \mathrm{~mm} / \mathrm{min}$ was used. Specimens have been tested in bending either after their production (non-impacted samples) or after the low-velocity impact tests (6 J and $27 \mathrm{~J}$ sample series) to measure their residual flexural strength. Mechanical tests have been performed on a Zwick/Roell Z010 (Ulm, Germany) universal testing machine equipped with a $10 \mathrm{kN}$ load cell.

Low velocity impact tests were conducted using an instrumented drop-weight impact testing machine (model Fractovis Plus from CEAST - Italy) equipped with a hemispherical tip (diameter $12.7 \mathrm{~mm}$ ). All tests were performed putting the sample on a stainless steel annular ring (internal diameter $40 \mathrm{~mm}$, outer diameter $60 \mathrm{~mm}$ ). Two impact energy values were used, namely $6 \mathrm{~J}$ and $27 \mathrm{~J}$. The first impact energy value was chosen in order to simulate the damage induced during service or maintenance on the composite structure. This type of damage is usually barely visible and can occur during service life, maintenance or mounting of the part. The second impact energy value was chosen after some preliminary perforation tests as the energy corresponding to the load peak of the COMP laminate. This allowed the direct comparison of the damage induced in a IGIS laminate under impact conditions capable of seriously damaging the fully compatibilized laminate (COMP). A minimum of 4 samples for each composition, measuring $80 \mathrm{~mm} \times 80 \mathrm{~mm}$ and cut from the prepared laminates, were tested and their mean values and variance were calculated.

Microtomographic image acquisition has been performed using an UltraTom CT scanner manufactured by RX Solutions (France). The system consists in a Hamamatsu micro focus sealed X-ray tube operating at $20-150 \mathrm{kV} / 0-500 \mu \mathrm{A}$, within a maximum power of
75 W. A precision object manipulator has been used for positioning and rotating the sample during the acquisition of tomographic data. $\mathrm{X}$-rays generated by the source diverge (cone beam) thus providing the possibility to magnify the sample by playing with the sample position with respect to the generator and/or the detector, both also movable to cover a large range of magnifications. A $16 \mu \mathrm{m}$ resolution has been used for the acquisitions in this work, with an accelerating voltage of $70 \mathrm{kV}$ and a beam current of $428 \mu \mathrm{A}$. The flat panel detector, consisting in an X-ray CsI scintillator screen settled on an amorphous silicon layer, has $1920 \times 1536$ pixels with a pixel size of $127 \mu \mathrm{m}$. The X-ray shadow projections are digitized with 65536 brightness gradations ( 16 bits) and recorded in TIFF format. The image acquisition time was about $2 \mathrm{~h}$ per specimen. For 3D reconstruction, X-ray images were acquired from 1440 rotation views over $360^{\circ}$ of rotation $\left(0.25^{\circ}\right.$ rotation step). The reconstruction was performed using an algorithm based on the filtered backprojection procedure for Feldkamp cone beam geometry.

Pre- and post-impact flexural tests have been monitored by acoustic emission until the occurrence of the final fracture using an AMSY- 5 AE system by Vallen Systeme GmbH (Icking, Germany). The $\mathrm{AE}$ acquisition settings used throughout this experimental work are as follows: threshold $=35 \mathrm{~dB}$, Rearm Time $(\mathrm{RT})=0.4 \mathrm{~ms}$, Duration Discrimination Time $(\mathrm{DDT})=0.2 \mathrm{~ms}$ and total gain $=34 \mathrm{~dB}$. This threshold level has been defined from a 30 min track record of the background noise, with the AE setup configuration actually used, and has been set $6 \mathrm{~dB}$ above the maximum level of the recorded spurious signal from the electronic system. Two broad-band (100-1500 kHz, Fujicera 1045 S) PZT AE sensors have been used. The sensors have been placed on the surface of the specimens at both ends to allow linear localization, with silicone grease as coupling agent.

\section{Results and discussion}

\subsection{Physical properties of laminates}

Laminates showed physical properties close to the target values (Table 2). Their thickness was within the $\pm 10 \%$ of the target value, the lowest and highest thickness being exhibited by the COMP and the NEAT samples, respectively. The fibre volume content was within $\pm 10 \%$ of the target value. Composite cross-sections were checked to detect the presence of voids within fibre bundles or in the matrix. From several acquisitions no voids were detected and all bundles appeared to be well impregnated by the matrix. Tests were also performed to measure the percentage of voids with digestion methodology and results were all below the required $2 \%$ limit of acceptance.

SEM morphological analysis, performed on fractured surfaces of laminates, is reported in Fig. 1, where the alternation of neat (in cyan) and compatibilized (in orange) layers qualitatively resembles the strong (COMP type, orange) and weak (NEAT type, cyan) interface strength through the laminate section. The composite prepared with not compatibilized polymeric layers (NEAT micrograph in Fig. 1) showed very long protruding fibres, which hinder the distinction of the different reinforcing layers. The poor fibre/ polymer interface, allowing the slippage of fibres during the laminate deflection, delocalizes the fibres breakage. On the contrary, in fully compatibilized laminates (COMP micrograph in Fig. 1) fibres bundles are clearly distinguished: very short fibres protrude from the fractured surface and often the fracture sharply passes through the bundle. This is an evidence that, during the laminate failure, crack propagation through fibres in compatibilized layers is very fast and straight through the laminate. These opposite behaviours are visible in IGIS laminates, where characteristic fibres fracture surfaces of neat and compatibilized layers can be identified and 
Table 2

Physical properties of laminates.

\begin{tabular}{lllll}
\hline Sample & $\begin{array}{l}\text { Thickness } \\
(\mathrm{mm})\end{array}$ & $\begin{array}{l}\text { Density } \\
\left(\mathrm{g} / \mathrm{cm}^{3}\right)\end{array}$ & $\begin{array}{l}\mathrm{V}_{\mathrm{f}} \\
(\%)\end{array}$ & $\begin{array}{l}\text { Voids Content } \\
(\%)\end{array}$ \\
\hline NEAT & $3.63 \pm 0.04$ & $1.59 \pm 0.01$ & $42.1 \pm 0.5$ & $0.8 \pm 0.3$ \\
COMP & $3.05 \pm 0.03$ & $1.73 \pm 0.01$ & $49.9 \pm 0.3$ & $0.3 \pm 0.2$ \\
HNC & $3.43 \pm 0.03$ & $1.63 \pm 0.01$ & $45.2 \pm 0.6$ & $0.4 \pm 0.2$ \\
HCN & $3.12 \pm 0.02$ & $1.63 \pm 0.01$ & $45.3 \pm 0.4$ & $0.4 \pm 0.2$ \\
HNCN & $3.14 \pm 0.02$ & $1.63 \pm 0.01$ & $47.5 \pm 0.7$ & $0.4 \pm 0.2$ \\
HCNC & $3.41 \pm 0.02$ & $1.67 \pm 0.01$ & $45.7 \pm 0.4$ & $0.5 \pm 0.2$ \\
HX & $3.30 \pm 0.03$ & $1.67 \pm 0.01$ & $47.2 \pm 0.5$ & $0.6 \pm 0.2$ \\
\hline
\end{tabular}

associated to the stacking sequence. Exploiting the interface strength gradation through the thickness, shown in Fig. 1, it induces unexpected structural behaviours, as shown in the following.

\subsection{Flexural properties before low velocity impacts}

Mean value and variance of flexural parameters evaluated before impacts for all configurations are reported in Table 3. Flexural tests always led to the breakage of the upper side of the sample [17]. The marked damaging of the composite in the upper side comes from the compressive failure of glass fibres and occurred at a lower stress in non compatibilized composites with respect to compatibilized ones. As expected, the presence of the coupling agent had a positive effect on both flexural modulus and flexural strength due to the increased capability of transfer loads between matrix and fibres. In this regard, the authors specifically investigated in a previous work the effect of the coupling agent content on static and impact properties of matrices and glass fibre reinforced composites and found that a limited increase of both flexural modulus and strength occurred with a maleated PP content higher than $2 \%$ by weight [16]. Although part of the improvement could be related to the slightly higher amount of reinforcing fibres, the COMP laminate clearly showed improved performances with respect to the NEAT one (Table 3). In particular the flexural strength resulted to be strongly increased in presence of the coupling agent because of the enhanced load transfer between the matrix and the woven fabric through the interface $[9,15]$.

IGIS composites showed flexural properties in between those exhibited by COMP and NEAT systems. Since the total amount of compatibilized and not compatibilized layers was the same in all configurations, the position and sequence with respect to the middle plane was responsible for the different stiffness and strength of the laminate. Samples with asymmetric matrix stacking (half neat and half compatibilized sections in HNC and HCN samples) showed very different results depending on the side on which the load was applied. Taking into account that the upper half of $\mathrm{HCN}$ and bottom half of HNC samples are constituted by layers of compatibilized polypropylene, the compressive failure of the upper side in HNC occurred earlier with respect to $\mathrm{HCN}$, resulting in a lower flexural strength. The flexural modulus and the flexural strength of HCN were comparable to those exhibited by the COMP laminate. Enhancing the flexural strength (higher interface

\section{Conventional Composite}

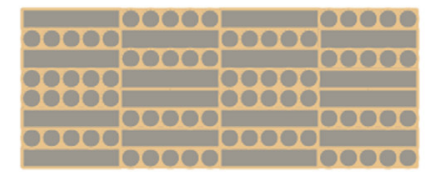

Interlaminar

Fibres
Hybridization

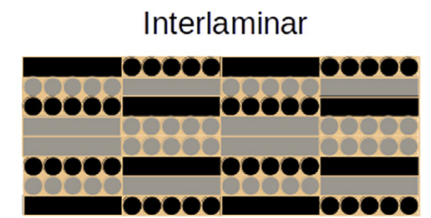

Matrix
Hybridization

Asymmetric

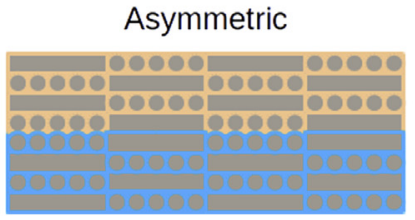

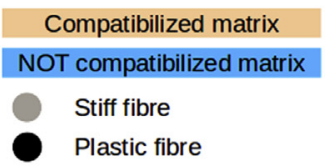

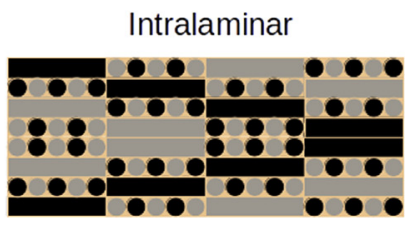

Symmetric

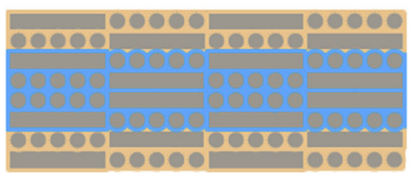

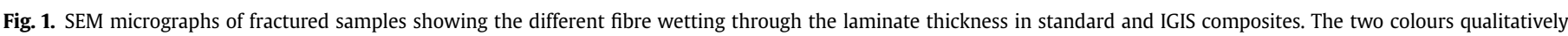

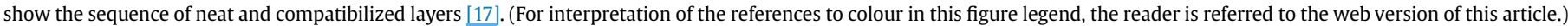

Table 3

Summary of flexural properties for all investigated thermoplastic-based composites.

\begin{tabular}{|c|c|c|c|c|c|c|}
\hline \multirow[b]{2}{*}{ Specimen } & \multicolumn{2}{|l|}{ Non-impacted } & \multicolumn{2}{|l|}{ Impact Energy: $6 \mathrm{~J}$} & \multicolumn{2}{|c|}{ Impact Energy: $27 \mathrm{~J}$} \\
\hline & $\begin{array}{l}\text { Flexural strength } \\
(\mathrm{MPa})\end{array}$ & $\begin{array}{l}\text { Flexural modulus } \\
\text { (GPa) }\end{array}$ & $\begin{array}{l}\text { Flexural strength } \\
(\mathrm{MPa})\end{array}$ & $\begin{array}{l}\text { Flexural modulus } \\
(\mathrm{GPa})\end{array}$ & $\begin{array}{l}\text { Flexural strength } \\
(\mathrm{MPa})\end{array}$ & $\begin{array}{l}\text { Flexural modulus } \\
\text { (GPa) }\end{array}$ \\
\hline NEAT & $115.88 \pm 3.38$ & $16.49 \pm 0.85$ & $103.27 \pm 3.36$ & $14.92 \pm 0.24$ & $86.33 \pm 3.37$ & $13.27 \pm 0.39$ \\
\hline COMP & $192.11 \pm 7.42$ & $20.92 \pm 0.32$ & $178.09 \pm 5.20$ & $20.04 \pm 0.84$ & $154.09 \pm 1.63$ & $17.14 \pm 0.19$ \\
\hline HNC & $116.47 \pm 1.32$ & $17.08 \pm 1.28$ & $110.00 \pm 4.15$ & $16.67 \pm 0.17$ & $92.26 \pm 2.89$ & $12.3 \pm 0.63$ \\
\hline $\mathrm{HCN}$ & $175.42 \pm 2.24$ & $20.51 \pm 0.69$ & $167.18 \pm 3.58$ & $19.08 \pm 0.36$ & $150.32 \pm 1.92$ & $18.13 \pm 0.51$ \\
\hline HNCN & $145.65 \pm 3.56$ & $19.23 \pm 0.87$ & $138.51 \pm 2.49$ & $17.58 \pm 0.49$ & $112.33 \pm 2.09$ & $12.62 \pm 0.42$ \\
\hline $\mathrm{HCNC}$ & $164.74 \pm 2.86$ & $16.87 \pm 0.29$ & $134.17 \pm 2.73$ & $15.78 \pm 0.53$ & $121.31 \pm 2.28$ & $15.18 \pm 0.34$ \\
\hline $\mathrm{HX}$ & $134.48 \pm 3.08$ & $15.79 \pm 0.47$ & $117.63 \pm 3.06$ & $15.25 \pm 0.12$ & $107.8 \pm 2.67$ & $13.36 \pm 0.29$ \\
\hline
\end{tabular}


Table 4

Average value and variance of the main impact parameters evaluated from impact tests performed at $6 \mathrm{~J}$.

\begin{tabular}{|c|c|c|c|c|c|}
\hline Sample & $\begin{array}{l}\text { Peak Load } \\
(\mathrm{N})\end{array}$ & $\begin{array}{l}\text { Peak Displacement } \\
(\mathrm{mm})\end{array}$ & $\begin{array}{l}\text { Absorbed Energy } \\
\text { (J) }\end{array}$ & $\begin{array}{l}\text { Recovered Energy } \\
\text { (J) }\end{array}$ & $\begin{array}{l}\text { Residual Displacement } \\
(\mathrm{mm})\end{array}$ \\
\hline NEAT & $3732 \pm 92$ & $2.8 \pm 0.2$ & $3.4 \pm 0.1$ & $2.6 \pm 0.1$ & $0.6 \pm 0.1$ \\
\hline COMP & $4045 \pm 65$ & $2.7 \pm 0.1$ & $3.0 \pm 0.1$ & $3.0 \pm 0.1$ & $0.5 \pm 0.1$ \\
\hline HNC & $3854 \pm 68$ & $2.7 \pm 0.1$ & $3.2 \pm 0.1$ & $2.8 \pm 0.1$ & $0.5 \pm 0.1$ \\
\hline $\mathrm{HCN}$ & $3732 \pm 57$ & $2.8 \pm 0.1$ & $3.3 \pm 0.1$ & $2.7 \pm 0.1$ & $0.5 \pm 0.1$ \\
\hline $\mathrm{HNCN}$ & $3923 \pm 62$ & $2.7 \pm 0.1$ & $3.1 \pm 0.1$ & $2.9 \pm 0.1$ & $0.5 \pm 0.1$ \\
\hline $\mathrm{HCNC}$ & $3871 \pm 72$ & $2.7 \pm 0.1$ & $3.2 \pm 0.1$ & $2.8 \pm 0.1$ & $0.5 \pm 0.1$ \\
\hline $\mathrm{HX}$ & $3836 \pm 97$ & $2.7 \pm 0.2$ & $3.3 \pm 0.1$ & $2.7 \pm 0.1$ & $0.5 \pm 0.1$ \\
\hline
\end{tabular}

strength) on the upper half of the composite and permitting fibre slipping (lower interface strength) in the lower half allowed a higher strain of the laminate before failure. Laminates with a symmetric interface strength were also prepared (HNCN, HCNC, $\mathrm{HX}$ ). The HX configuration, with a complex sequence of interface strengths exhibited the lowest flexural modulus among all IGIS composites, and one of the lowest flexural strengths that resulted significantly lower than COMP and HCN composites.

\subsection{Low-velocity impact tests and MicroCT analyses}

The low velocity impact characterization of NEAT and COMP laminates showed an opposite behaviour with respect to the static four point bending test. At low impact energy $E_{i}=6 \mathrm{~J}$ (Table 4) COMP laminate showed a higher peak load (4045 N) and a higher recovered energy ( $3.0 \mathrm{~J}$ ) with respect to NEAT laminate (3732 $\mathrm{N}$ and $2.6 \mathrm{~J}$, respectively) in accordance with the higher stiffness of the composite structure (Fig. 2A and Fig. 3A). The recovered energy represents the amount of energy elastically stored by the composite structure and then returned after the peak load. It is calculated as the difference between the impact energy and the total energy absorbed during the impact event, thus higher recovered energy means lower irreversible mechanical phenomena. Since the impact energy was the same for all samples, higher values of the recovered energy are a direct evidence of lower damages induced in the composite structure through dissipating phenomena like matrix cracking, fibre slipping and delaminations. The compatibilized laminate dissipated $50 \%$ of the impact energy versus the $57 \%$ of the NEAT laminate meaning that it incurred in lower damaging. In fact, as previously reported the very strong interface between compatibilized polymer and glass fibres hinders typical dissipative pullout phenomena because they cannot move from their position [16].

IGIS laminates showed intermediate results in the same impact conditions, with the HNCN laminate showing the best result among them. In fact, it exhibited the load peak at $3923 \mathrm{~N}$ and a recovered energy of $2.9 \mathrm{~J}$, only $3 \%$ lower than that of the COMP configuration. The highest displacement at peak load, which is the maximum deflection of the laminate during the impact event, was exhibited by the NEAT laminate. Almost all IGIS configurations behaved as the COMP composite in terms of peak and residual displacements, showing comparable external damages.

The comparison of MicroCT sections of the impacted region shows that the indentation of the laminates is small after impacting at $E_{i}=6 \mathrm{~J}$ and there is no evidence of broken fibres or damages through the thickness (Fig. 4). The NEAT laminate showed a slightly higher indentation after the impact.

Although the use of IGIS layered configurations allowed to obtain impact responses comprised between the extremes of conventional laminate configurations at $\mathrm{E}_{\mathrm{i}}=6 \mathrm{~J}$ (see Table 4), at $\mathrm{E}_{\mathrm{i}}=27 \mathrm{~J}$ relevant differences were detected (Table 5). The NEAT laminate performed better than COMP laminate, exhibiting both higher peak load (8035 N versus $6631 \mathrm{~N},+21 \%$ ) and recovered energy (10.1 J versus $7.5 \mathrm{~J},+34 \%$ ). The impact response of the COMP laminate showed a jagged shape after the peak load in the Force vs Displacement curve at $E_{i}=27 \mathrm{~J}$, as a direct consequence of extensive fibre breakage. This was also clearly detected by means of the micro-computed tomographic analysis that revealed this damage mode through the laminate thickness (Fig. 5, COMP 27 J sample). The majority of reinforcing layers was severely damaged and only few layers on top remained undamaged. On the contrary, the NEAT composite (Fig. 5, NEAT $27 \mathrm{~J}$ sample) was clearly able to better tolerate the impact energy with the occurrence of fibre breakage only in three backside layers. This result was in direct relationship with the trend of the Force versus Displacement curve after the
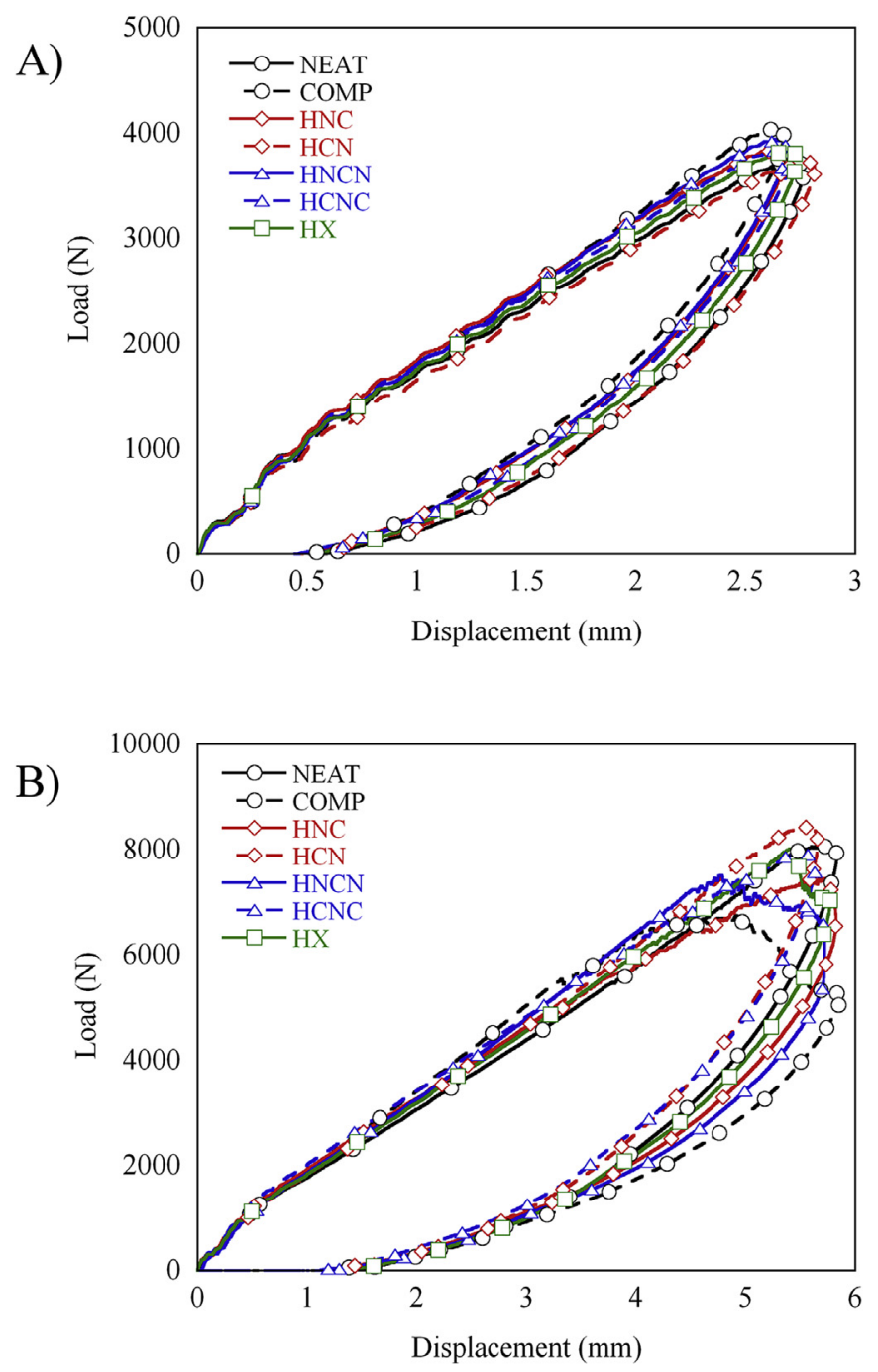

Fig. 2. Load versus displacement curves from low velocity impact tests as a function of the stacking sequence: A) Impact energy $=6 \mathrm{~J}, \mathrm{~B}$ ) Impact Energy $=27 \mathrm{~J}$. 
A)
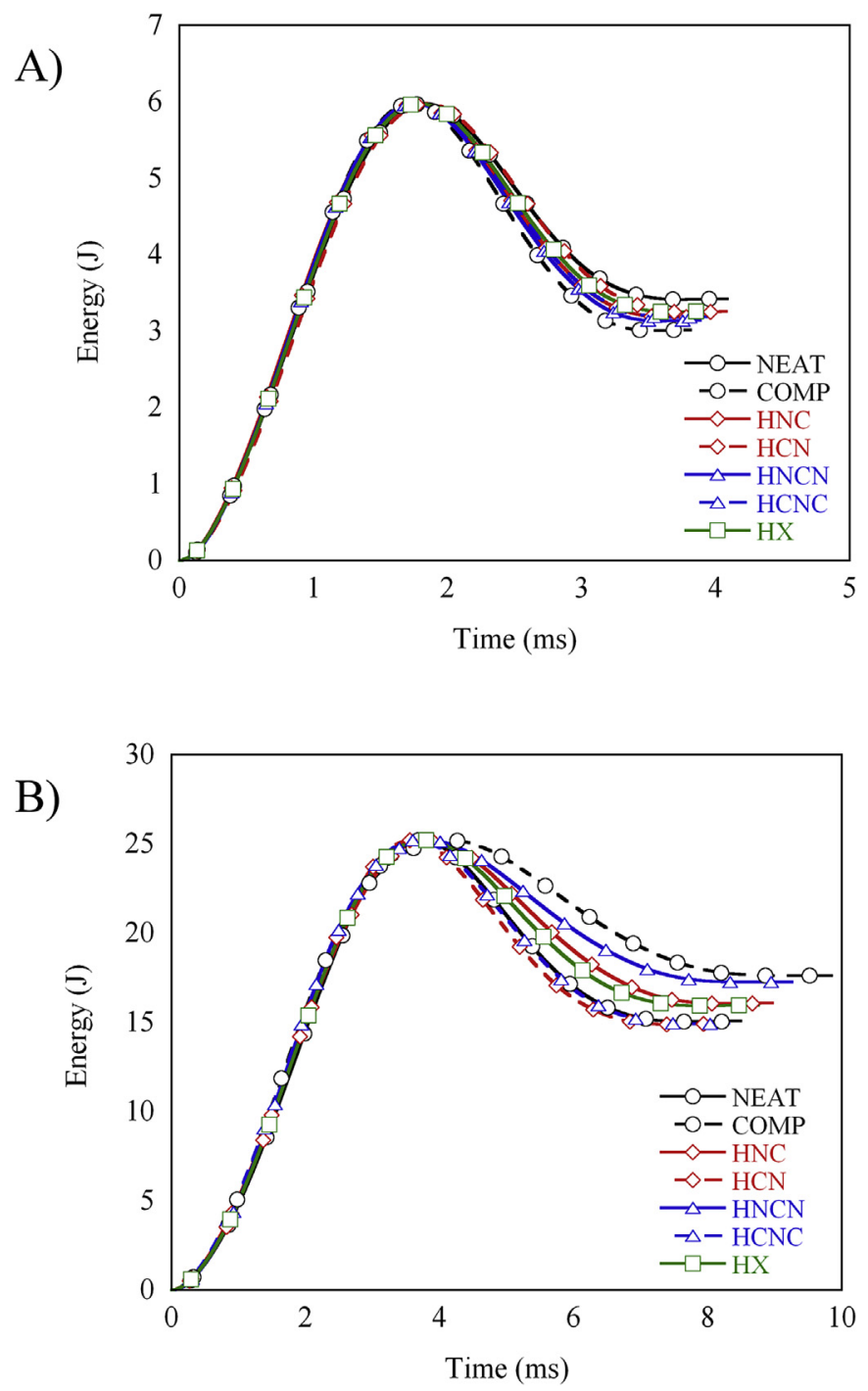

Fig. 3. Energy versus Time curves obtained from low velocity impact tests as a function of the stacking sequence: A) Impact energy $=6 \mathrm{~J}, \mathrm{~B}$ ) Impact Energy $=27 \mathrm{~J}$.

peak load (Fig. 2B). The higher displacement at peak load exhibited by COMP confirmed its lower damage tolerance with respect to the NEAT composite, as well as the lower capability of the former to recover elastic energy (Table 5). All IGIS laminates showed load peaks higher than COMP (with performance gains from $12 \%$ to $27 \%$, and HCNC even better performing than the NEAT laminate). HNC, HNCN and HX samples showed comparable displacements at peak load to COMP but higher recovered energies $(9.1 \mathrm{~J}, 8.2 \mathrm{~J}$ and $9.3 \mathrm{~J}$

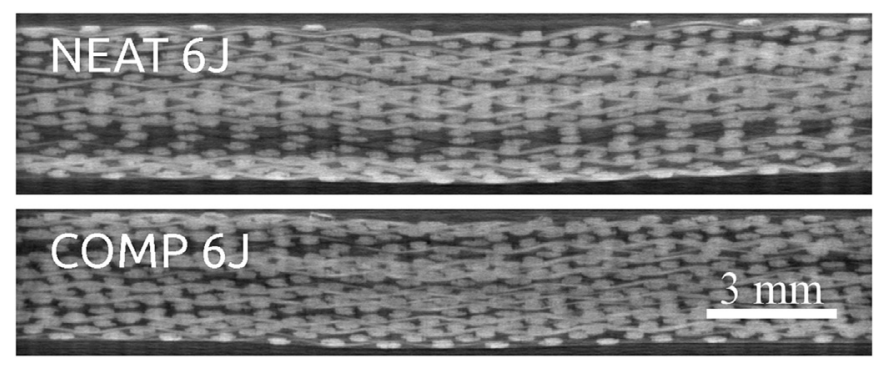

Fig. 4. Microphotographs from MicroCT scans of NEAT and COMP laminates after the low energy impact $\left(E_{i}=6 \mathrm{~J}\right)$. respectively). $\mathrm{HCN}$ and $\mathrm{HCNC}$ laminates showed the lowest peak displacements and the highest recovered energies ( $+37 \%$ for both configurations with respect to COMP), and their Load versus Displacement curves did not show significant evidence of fibre breakage. Furthermore, their displacement at peak load almost coincided with the maximum displacement, meaning that limited damaging occurred in the laminate at $\mathrm{E}_{\mathrm{i}}=27 \mathrm{~J}$. HCN and HCNC configurations exhibited a sound improvement over the impact performance of the compatibilized laminate and were able to preserve the integrity of most of the reinforcing fibres.

The MicroCT mid sections of IGIS samples impacted at $E_{i}=27 \mathrm{~J}$ are shown in Fig. 5. The topology of the damage is coherent with the results from the impact curves. Extended damages are present in the compatibilized laminate (COMP $27 \mathrm{~J}$ ). In particular, a large indentation of the impacted surface and wide and deep fibre breakage through the laminate thickness from the bottom to almost the top surface are clearly detectable. On the contrary, the NEAT laminate showed few damages, almost limited at the bottom three fabric layers. No clear damaging is visible in the inner part of the laminate as a result of the slipping of fibres into the matrix. By means of this mechanism the load is spread through a larger volume of the composite structure and renders the laminate capable of absorbing a larger amount of energy with respect to a fully compatibilized structure because friction between fibres and matrix is allowed to occur. Since the fibre/matrix interface is weak, there is no crack propagation between matrix and fibres and fibre breakage is retarded, as well as fibres pull-out. All IGIS configurations exhibited lower damages with respect to COMP laminate. Among them, HNC and HNCN reported the largest fibre breakage below the impacted zone, with a damage topology similar to that of COMP but always limited to the lower half of the laminate thickness. HCN, $\mathrm{HCNC}$ and HX reported very limited fibre breakage, comparable to, if not lower than, the NEAT configuration.

It is interesting to note the very different impact behaviour between $\mathrm{HNC}$ and $\mathrm{HCN}$. The former configuration has been impacted on the not compatibilized side. Its bottom half, which undergoes large tensile and shear strains during the dart penetration, is made of compatibilized layers. They are stiff and do not have large strains at break, hence they cannot allow the compliance of the fabric such as in the upper not compatibilized zone. Conversely, the presence in HCN of a thick zone of not compatibilized layers in the bottom half allowed to easily accommodate the tendency of the fibres to slide in the PP matrix and hindered a fast propagation of fractures and cracks through matrix and fibres.

The high values of recovered energy coupled with the absence of fibre breakage indicated that the matrix layering of HCN and HCNC can withstand much higher impact loads before the composite failure with respect to the conventional compatibilized laminate configuration (COMP). This result is related to the possibility of fibres to slip in not compatibilized layers thus dissipating energy through friction and retarding the occurrence of fibre breakage. The $\mathrm{HCN}$ configuration revealed the best overall performances among all IGIS designs but its asymmetric configuration can be used only if a preferential static or impact load direction can be identified. In case of symmetric loads the HCNC design is the most suitable layering. The detected impact performance of IGIS laminates highlighted that the use of the interlaminar gradation of the interface strength could be a very effective method to improve the damage resistance of thermoplastic composites without heavily affecting their static flexural performance.

\subsection{Post impact flexural properties}

Due to the high sensitivity of composite materials to concentrated impacts, dramatic loss in residual strength and in structural 
Table 5

Average value and variance of main parameters evaluated from impact tests performed at $27 \mathrm{~J}$.

\begin{tabular}{|c|c|c|c|c|c|}
\hline Sample & $\begin{array}{l}\text { Peak Load } \\
(\mathrm{N})\end{array}$ & $\begin{array}{l}\text { Peak Displacement } \\
(\mathrm{mm})\end{array}$ & $\begin{array}{l}\text { Absorbed Energy } \\
\text { (J) }\end{array}$ & $\begin{array}{l}\text { Recovered Energy } \\
\text { (J) }\end{array}$ & $\begin{array}{l}\text { Residual Displacement } \\
(\mathrm{mm})\end{array}$ \\
\hline NEAT & $8035 \pm 176$ & $5.8 \pm 0.3$ & $15.1 \pm 0.2$ & $10.1 \pm 0.2$ & $1.4 \pm 0.1$ \\
\hline COMP & $6631 \pm 92$ & $5.9 \pm 0.1$ & $17.7 \pm 0.2$ & $7.5 \pm 0.2$ & $1.1 \pm 0.1$ \\
\hline HNC & $7432 \pm 154$ & $5.8 \pm 0.3$ & $16.1 \pm 0.2$ & $9.1 \pm 0.2$ & $1.1 \pm 0.1$ \\
\hline $\mathrm{HCN}$ & $7506 \pm 108$ & $5.7 \pm 0.2$ & $14.9 \pm 0.2$ & $10.3 \pm 0.2$ & $1.3 \pm 0.1$ \\
\hline $\mathrm{HNCN}$ & $7951 \pm 143$ & $5.8 \pm 0.2$ & $17.3 \pm 0.2$ & $8.2 \pm 0.2$ & $1.1 \pm 0.1$ \\
\hline $\mathrm{HCNC}$ & $8437 \pm 164$ & $5.6 \pm 0.2$ & $14.9 \pm 0.2$ & $10.3 \pm 0.2$ & $1.1 \pm 0.1$ \\
\hline HX & $8055 \pm 204$ & $5.8 \pm 0.3$ & $15.9 \pm 0.2$ & $9.3 \pm 0.2$ & $1.3 \pm 0.1$ \\
\hline
\end{tabular}

integrity can occur when loads are applied after an impact event. Residual strengths in tension, compression, bending and fatigue will be reduced to varying degrees depending on the dominant damage mode. In order to obtain a better indication of the damage tolerance, which indicates a system's ability to perform postimpact, the normalized flexural strength (or flexural modulus) of each specimen is evaluated as the ratio of the mean strength (or flexural modulus) of the impacted specimen to the mean value of the flexural strength (or flexural modulus) of the undamaged specimen. Fig. 6A and Fig. $6 \mathrm{~B}$ show the normalized flexural modulus and strength, respectively, as a function of increasing impact energy, whilst in Table 3 the flexural properties of the laminates measured after impact are reported.

It can be clearly seen that the best performance in terms of both strength and stiffness is obtained for fully compatibilized composites (COMP), thus highlighting the positive role played by the coupling agent. As a general comment, all composites suffered from failures in the compression side that occurred at different stresses as a function of the interface strength. In this regard, NEAT composites offered the lowest performance due to the absence of significant stress transfer at the fibre/matrix interface.
The increasing trend of damaging for all laminates caused by low velocity impacts is matched by the reduction of the flexural strength and, to a greater extent, of the flexural modulus. Interface strength gradation proved to be a valuable approach to enhance the mechanical properties of thermoplastic-based composites, especially as regards the damage tolerance. The configurations can be ranked from the higher to the lower flexural strength in the following order: HCN $>$ COMP, HX $>$ HNC $>$ HNCN $>$ NEAT $>$ HCNC for the normalized residual strength and $\mathrm{HCNC}>\mathrm{HCN}>\mathrm{HX}>$ COMP $>$ NEAT $>$ HNC $>$ HNCN for the normalized residual modulus. As a general conclusion, with increasing impact energy, the best compromise in terms of both quasi-static properties and damage tolerance appears to be the $\mathrm{HCN}$ configuration. These results can be linked to the different mechanisms responsible for energy dissipation and the development of damage during subsequent flexural loading that is known to introduce a complex stress pattern in the specimen. Therefore the effect of the damage on residual strength is less easy to analyse and to this purpose the time evolution of different failure modes was studied through the analysis of acoustic emission signals.
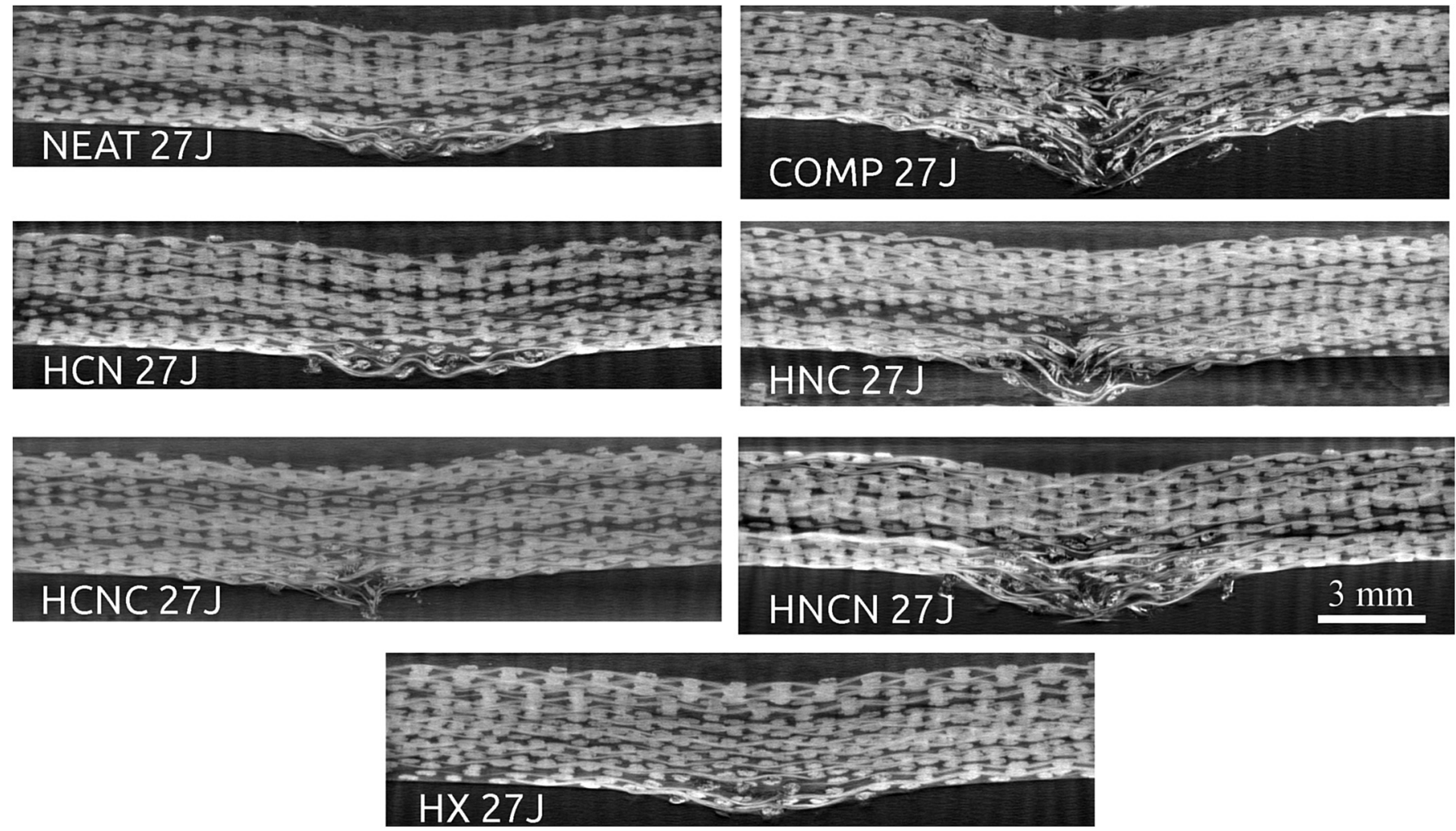

Fig. 5. Microphotographs from MicroCT scans of NEAT and COMP laminates after the impact at $E_{\mathrm{i}}=27 \mathrm{~J}$. 

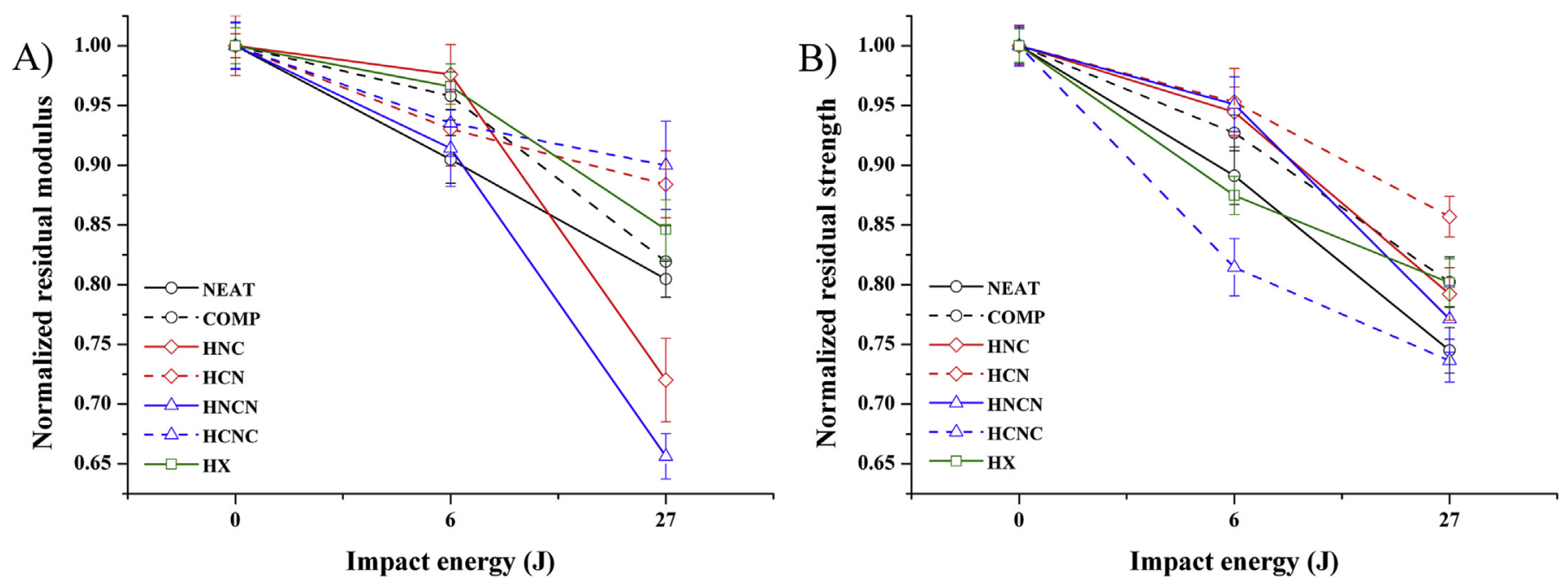

Fig. 6. Normalized residual flexural modulus (A) and strength (B) as a function of impact energy.

\subsection{Acoustic emission analysis}

AE events amplitude and duration distributions for undamaged and impacted samples are reported in Fig. 7. Fig. 8 shows a comparison of the damage modes found in laminates at the end of flexural tests. For NEAT composites, all the damage is concentrated on the compression side and only at $27 \mathrm{~J}$ the failure tends to be localized and the impact damage seems to prevail over flexural loading. Looking at results from $\mathrm{AE}$ analysis, no signals of high amplitude $(>75 \mathrm{~dB})[41,47,48]$ were detected on neat or impacted samples, thus highlighting the limited occurrence of further fibre failures that can be responsible for the low strength offered by such composites. Most AE signals are in the ranges 35-50 dB and 0-50 $\mu$ s for amplitude and duration, respectively, which are usually ascribed to matrix cracking. These signals are reasonably located in the most critical zone that is the compression side of the specimens.

With increasing impact energy, there is a slight increase in signals of medium amplitude and duration (second and third intervals). This can be an indication of the absence of extensive delaminations produced to absorb impact energy. Isolated interfacial failures and matrix microcracking linked to failure in compression side (fibre microbuckling and kink bands) appear to be the main mechanisms responsible for the absorption of impact energy. This could explain the relatively low energy absorption at $\mathrm{E}_{\mathrm{i}}=27 \mathrm{~J}$.

Specimens with asymmetric matrix stacking sequence (HCN and HNC) exhibited different behaviours for both static and dynamic loading with $\mathrm{HCN}$ outperforming HNC configuration. Up to $E_{i}=6 \mathrm{~J}$ the failure of HCN laminates is still characterized by a failure in the compression side even though at $\mathrm{E}_{\mathrm{i}}=27 \mathrm{~J}$ the failure reached also the tensile side. The better behaviour can be ascribed to the fact that the compression side is compatibilized and therefore offers a greater strength. AE analysis revealed an increased number of signals of amplitude and duration belonging to the second and third interval that can be ascribed to interface failures with increasing impact energy, thus moving the overall failure from the compression to the tensile side. There is also evidence of signals related to fibre breakages due to the effect of compatibilizing agent. The better damage tolerance seems to be the result of a delay in failure of the compression side due to the presence of a stronger interface adhesion. HNC configuration was found to offer inferior static and damage tolerance properties compared to HCN layering sequence due to the presence of a non compatibilized zone in the critical compression side, where most of damage concentrated, without a significant transition to the tensile side. This is a clear indication that the composite was not exploited to a great extent, thus confirming the lower mechanical properties. Compared to $\mathrm{HCN}$, there are more signals of higher duration that indicate the development of extensive delaminations, which are responsible for the higher absorption of energy for this configuration. COMP laminates exhibited an acceptable damage tolerance and AE signature was characterized by the presence of signals pointing to extensive fibre breakages that trigger delaminations diffused in the whole volume of the specimens. It is also possible to note that the stronger interface strength allowed an efficient stress transfer that resulted in a failure not limited to the compressed half section. In fact, the whole section was involved in the fracture process up to the tensile face even for not impacted samples.

Laminates with symmetric interface strength highlighted the positive role played by the compatibilized core ( $\mathrm{HNCN})$. In this case the $\mathrm{AE}$ signals up to $\mathrm{E}_{\mathrm{i}}=6 \mathrm{~J}$ are concentrated in the lower ranges for both amplitude and duration due to a diffused matrix microcracking. With increasing impact energy, the behaviour resembles that of the COMP laminates (increasing composite section involved in the final failure) with a lower occurrence of signals of high amplitude and duration, thus suggesting an increasing damage (interface failures and microcracks) in the non-compatibilized skins. The presence of a non-compatibilized core (HCNC) is responsible for the lower damage tolerance compared to $\mathrm{HNCN}$ laminates. For HCNC composites, there was an increasing number of $\mathrm{AE}$ signals with increasing impact energy due to the failure of non-compatibilized core. The significant number of signals detected as a function of impact energy can be ascribed to diffused damages that coalesce to become critical for the core that, once failed, triggers the failure of the tensile side already damaged by impact loagding. The HX configuration exhibited the highest number of $\mathrm{AE}$ signals among the investigated configurations, thus highlighting the presence of a diffused damage due to the several interfaces present in the layering sequence. Damage partition among internal interfaces enables HX laminates, although less resistant than HCNC and HNCN, to show a lower degradation of their strength at higher impact energy also considering the limited extent of damage induced by impulsive loading. Also in this case the failure was a mixed compression-tensile mode with a pronounced tensile mode present even at very low energy $\left(E_{i}=6 \mathrm{~J}\right)$ as 


$$
\text { A }
$$



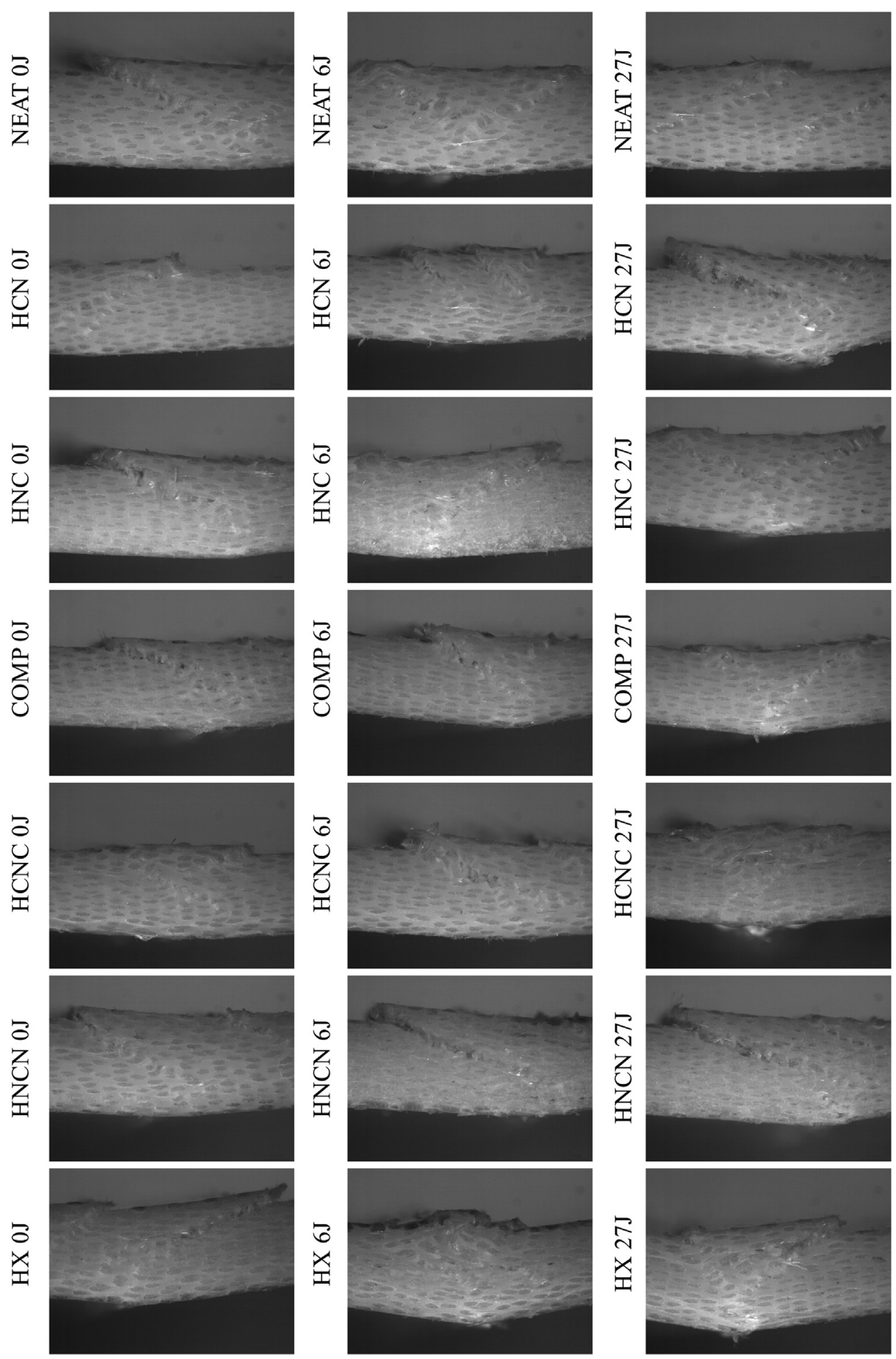

Fig. 8. Damage modes observed in laminates once failed in bending.

observed for $\mathrm{HCN}$ composites, but this time likely due to the combination of the limited but diffused damage available over the whole composite.

For a general conclusion about the previous results, it may be inferred that disposing a non-compatibilized core between two compatibilized skins provides in principle better static strength but lower damage tolerance to low velocity impacts. For impact energies approaching penetration, more complex layering sequences, involving intercalated compatibilized and non-compatibilized matrix layers, such as in HX laminates, may offer better predictability of impact damage propagation in composites and higher residual properties. 


\section{Conclusions}

Hybrid thermoplastic composites based on polypropylene and glass fibre woven fabrics were prepared according to a new hybridization approach, based on the gradation of the interlaminar interface strength (IGIS). IGIS laminates were prepared by properly alternating layers of compatibilized or not compatibilized polypropylene films in symmetric or asymmetric sequences, without affecting the reinforcement configuration.

The presence of the coupling agent increases the capability to transfer loads from the matrix to the fibres. This results in improved flexural modulus and, to a higher extent, flexural strength but in decreased low velocity impact resistance, leading to fibres breakage and lower recovery of the elastic energy. The reduced interface strength in not compatibilized composites allows the occurrence of fibres pull-out phenomena which dissipate a high amount of energy through sliding mechanisms and friction between fibres and matrix.

IGIS laminates exhibited static flexural properties comprised between those of fully neat and fully compatibilized composites. One configuration (HCN) showed a flexural response quite close to that of the compatibilized laminate. The low velocity impact characterization, performed at $6 \mathrm{~J}$ and $27 \mathrm{~J}$, demonstrated that grading the matrix/fibres interface strength can be an effective way to retain good mechanical properties while allowing significant increase in the impact damage tolerance. In fact, IGIS configurations showed very limited damaging of fibres under conditions where the fully compatibilized composite was almost broken, as clearly shown by the microCT analysis. Among all configurations the $\mathrm{HCN}$ one exhibited the highest peak load and the highest recovered energy, outperforming the composites based on compatibilized and not compatibilized PP.

Acoustic emission monitoring of post-impact flexural tests offered some insights into the development of damage and confirmed the favourable balance of static and damage tolerance properties of the asymmetric matrix stacking sequence $(\mathrm{HCN})$. In addition, due to the highest number of AE signals among the configurations investigated ascribed to a diffused damage, the intercalated stacking sequence proved to be a suitable damage tolerant material with increasing impact energy.

\section{References}

[1] Stewart R. Thermoplastic composites - recyclable and fast to process. Reinf Plast 2011;55:22-8. http://dx.doi.org/10.1016/S0034-3617(11)70073-X.

[2] Yang Y, Boom R, Irion B, van Heerden DJ, Kuiper P, de Wit H. Recycling of composite materials. Chem Eng Process Process Intensif 2012;51:53-68. http://dx.doi.org/10.1016/i.cep.2011.09.007.

[3] Zarei H, Kröger M, Albertsen H. An experimental and numerical crashworthiness investigation of thermoplastic composite crash boxes. Compos Struct 2008:85:245-57. http://dx.doi.org/10.1016/j.compstruct.2007.10.028.

[4] Robert M, Roy R, Benmokrane B. Environmental effects on glass fiber reinforced polypropylene thermoplastic composite laminate for structural applications. Polym Compos 2010;31:604-11. http://dx.doi.org/10.1002/pc.20834.

[5] Reis PNB, Ferreira JAM, Richardson MOW. Fatigue damage characterization by NDT in polypropylene/glass fibre composites. Appl Compos Mater 2011;18: 409-19. http://dx.doi.org/10.1007/s10443-010-9172-9.

[6] Mulle M, Wafai H, Yudhanto A, Lubineau G, Yaldiz R, Schijve W, et al. Process monitoring of glass reinforced polypropylene laminates using fiber Bragg gratings. Compos Sci Technol 2016;123:143-50. http://dx.doi.org/10.1016 j.compscitech.2015.12.020.

[7] Etcheverry M, Barbosa SE. Glass fiber reinforced polypropylene mechanical properties enhancement by adhesion improvement. Mater (Basel) 2012;5: 1084-113. http://dx.doi.org/10.3390/ma5061084.

[8] Boufaida Z, Farge L, André S, Meshaka Y. Influence of the fiber/matrix strength on the mechanical properties of a glass fiber/thermoplastic-matrix plain weave fabric composite. Compos Part A Appl Sci Manuf 2015;75:28-38. http://dx.doi.org/10.1016/j.compositesa.2015.04.012.

[9] Russo P, Acierno D, Simeoli G, Iannace S, Sorrentino L. Flexural and impact response of woven glass fiber fabric/polypropylene composites. Compos Part B Eng 2013;54:415-21. http://dx.doi.org/10.1016/j.compositesb.2013.06.016.
[10] González EV, Maimí P, Sainz de Aja JR, Cruz P, Camanho PP. Effects of interply hybridization on the damage resistance and tolerance of composite laminates. Compos Struct 2014;108:319-31. http://dx.doi.org/10.1016/j.compstruct. 2013.09.037.

[11] Zhang J, Chaisombat K, He S, Wang CH. Hybrid composite laminates reinforced with glass/carbon woven fabrics for lightweight load bearing structures. Mater. Des 2012;36:75-80. http://dx.doi.org/10.1016/i.matdes.2011. 11.006.

[12] Hosur MV, Adbullah M, Jeelani S. Studies on the low-velocity impact response of woven hybrid composites. Compos Struct 2005;67:253-62. http:// dx.doi.org/10.1016/j.compstruct.2004.07.024.

[13] Dehkordi MT, Nosraty H, Shokrieh MM, Minak G, Ghelli D. Low velocity impact properties of intra-ply hybrid composites based on basalt and nylon woven fabrics. Mater. Des 2010;31:3835-44. http://dx.doi.org/10.1016/ j.matdes.2010.03.033.

[14] Parandaman P, Jayaraman M. Experimental investigation on the mechanical properties of jute/sisal/glass and jute/banana/glass hybrid composite materials. Eur J Appl Sci 2015;7:138-44. http://dx.doi.org/10.5829/idosi.ejas. 2015.7.3.22252.

[15] Simeoli G, Acierno D, Meola C, Sorrentino L, Iannace S, Russo P. The role of interface strength on the low velocity impact behaviour of $\mathrm{PP} /$ glass fibre laminates, Compos. Part B Eng 2014;62:88-96. http://dx.doi.org/10.1016 j.compositesb.2014.02.018.

[16] Russo P, Simeoli G, Sorrentino L, Iannace S. Effect of the compatibilizer content on the quasi-static and low velocity impact responses of glass woven fabric/ polypropylene composites. Polym Compos 2016;37:2452-9. http:// dx.doi.org/10.1002/pc.23430.

[17] Sorrentino L, Simeoli G, Iannace S, Russo P. Mechanical performance optimization through interface strength gradation in PP/glass fibre reinforced composites. Compos Part B Eng 2015;76:201-8. http://dx.doi.org/10.1016/ j.compositesb.2015.02.026.

[18] Boccardi S, Meola C, Carlomagno GM, Sorrentino L, Simeoli G, Russo P. Effects of interface strength gradation on impact damage mechanisms in polypropylene/woven glass fabric composites. Compos Part B Eng 2016;90: 179-87. http://dx.doi.org/10.1016/j.compositesb.2015.12.004.

[19] Yu B, Bradley RS, Soutis C, Hogg PJ, Withers PJ. 2D and 3D imaging of fatigue failure mechanisms of 3D woven composites. Compos Part A Appl Sci Manuf 2015;77:37-49. http://dx.doi.org/10.1016/j.compositesa.2015.06.013.

[20] Quan Z, Larimore Z, Qin X, Yu J, Mirotznik M, Byun JH, et al. Microstructural characterization of additively manufactured multi-directional preforms and composites via X-ray micro-computed tomography. Compos Sci Technol 2016;131:48-60. http://dx.doi.org/10.1016/j.compscitech.2016.05.015.

[21] Stock SR. X-ray microtomography of materials. Int Mater. Rev 1999;44: 141-64. http://dx.doi.org/10.1179/095066099101528261.

[22] Schilling PJ, Karedla BR, Tatiparthi AK, Verges MA, Herrington PD. X-ray computed microtomography of internal damage in fiber reinforced polymer matrix composites. Compos Sci Technol 2005;65:2071-8. http://dx.doi.org/ 10.1016/j.compscitech.2005.05.014.

[23] El Mourid A, Ganesan R, Brochu M, Lévesque M. Effect of temperature on the failure modes of a triaxially braided polymer matrix composite. Int I Solids Struct 2016;97-98:1-15. http://dx.doi.org/10.1016/j.ijsolstr.2016.08.005.

[24] Nixon-Pearson OJ, Hallett SR. An investigation into the damage development and residual strengths of open-hole specimens in fatigue. Compos Part A Appl Sci Manuf 2015;69:266-78. http://dx.doi.org/10.1016/j.compositesa.2014. 11.013.

[25] Sket F, Enfedaque A, Díaz López C, González C, Molina-Aldareguía J, LLorca J. $\mathrm{X}$-ray computed tomography analysis of damage evolution in open hole carbon fiber-reinforced laminates subjected to in-plane shear. Compos Sci Technol 2016;133:40-50. http://dx.doi.org/10.1016/i.compscitech.2016. 06.012.

[26] Symons DD. Characterization of indentation damage in 0/90 lay-up T300/914 CFRP. Compos Sci Technol 2000;60:391-401. http://dx.doi.org/10.1016/ S0266-3538(99)00139-6.

[27] Penumadu D, Kim F, Bunn J. Damage of composite materials subjected to projectile penetration using high resolution x-ray micro computed tomography. Exp Mech 2016;56:607-16. http://dx.doi.org/10.1007/s11340-0150085-2.

[28] Ferrante L, Tirillò J, Sarasini F, Touchard F, Ecault R, Vidal Urriza MA, et al. Behaviour of woven hybrid basalt-carbon/epoxy composites subjected to laser shock wave testing: preliminary results. Compos Part B Eng 2015;78: 162-73. http://dx.doi.org/10.1016/j.compositesb.2015.03.084.

[29] Dunkers JP, Sanders DP, Hunston DL, Everett MJ, Green WH. Comparison of optical coherence tomography, x-ray computed tomography, and confocal microscopy results from an impact damaged epoxy/e-glass composite. J Adhes 2002;78:129-54. http://dx.doi.org/10.1080/00218460210386.

[30] Fidan S, Snmazçelik T, Avcu E. Internal damage investigation of the impacted glass/glassaramid fiber reinforced composites by micro-computerized tomography. NDT E Int 2012;51:1-7. http://dx.doi.org/10.1016/j.ndteint. 2012.07 .005$.

[31] Nash NH, Young TM, Stanley WF. An investigation of the damage tolerance of carbon/Benzoxazine composites with a thermoplastic toughening interlayer. Compos Struct 2016;147:25-32. http://dx.doi.org/10.1016/j.compstruct. 2016.03.015.

[32] Seidensticker DG, Kim K-S, Hahn HT, Jensen DW, Goering JC. Compressive behavior of a thermoplastic composite (GR/PEEK). J Thermoplast Compos 
Mater 1990;3:233-51. http://dx.doi.org/10.1177/089270579000300305.

[33] Srinivasan K, Jackson W, Smith B, Hinkley JA. Characterisation of damage modes in impacted thermoset and thermoplastic composites. J Reinf Plast Compos 1992;11:1111-26. http://dx.doi.org/10.1177/073168449201101004.

[34] Vieille B, Casado VM, Bouvet C. Influence of matrix toughness and ductility on the compression-after-impact behavior of woven-ply thermoplastic- and thermosetting-composites: a comparative study. Compos Struct 2014;110: 207-18. http://dx.doi.org/10.1016/j.compstruct.2013.12.008.

[35] Richardson MOW, Wisheart MJ. Review of low-velocity impact properties of composite materials. Compos Part A Appl Sci Manuf 1996;27:1123-33. http:// dx.doi.org/10.1016/1359-835X(96)00074-7.

[36] Cantwell WJ, Morton J. The impact resistance of composite materials - a review. Composites 1991;22:347-62. http://dx.doi.org/10.1016/0010-4361(91) 90549-V.

[37] Rhead AT, Hua S, Butler R. Damage resistance and damage tolerance of hybrid carbon-glass laminates. Compos Part A Appl Sci Manuf 2015;76:224-32. http://dx.doi.org/10.1016/j.compositesa.2015.06.001.

[38] Selver E, Potluri P, Hogg P, Soutis C. Impact damage tolerance of thermoset composites reinforced with hybrid commingled yarns. Compos Part B Eng 2016;91:522-38. http://dx.doi.org/10.1016/j.compositesb.2015.12.035.

[39] Berges M, Léger R, Placet V, Person V, Corn S, Gabrion X, et al. Influence of moisture uptake on the static, cyclic and dynamic behaviour of unidirectional flax fibre-reinforced epoxy laminates. Compos Part A Appl Sci Manuf 2016;88: 165-77. http://dx.doi.org/10.1016/j.compositesa.2016.05.029.

[40] McCrory JP, Al-Jumaili SK, Crivelli D, Pearson MR, Eaton MI, Featherston CA et al. Damage classification in carbon fibre composites using acoustic emission: a comparison of three techniques. Compos Part B Eng 2015;68:424-30. http://dx.doi.org/10.1016/j.compositesb.2014.08.046.

[41] Barré S, Benzeggagh ML. On the use of acoustic emission to investigate damage mechanisms in glass-fibre-reinforced polypropylene. Compos Sc Technol 1994;52:369-76. http://dx.doi.org/10.1016/0266-3538(94)90171-6.

[42] Munoz V, Valès B, Perrin M, Pastor ML, Welemane H, Cantarel A, et al. Damage detection in CFRP by coupling acoustic emission and infrared thermography. Compos Part B Eng 2016;85:68-75. http://dx.doi.org/10.1016/j.compositesb. 2015.09.011.

[43] Doan DD, Ramasso E, Placet V, Zhang S, Boubakar L, Zerhouni N. An unsupervised pattern recognition approach for $\mathrm{AE}$ data originating from fatigue tests on polymer-composite materials. Mech Syst Signal Process 2015;64-65: 465-78. http://dx.doi.org/10.1016/i.ymssp.2015.04.011.

[44] Crivelli D, Guagliano M, Eaton M, Pearson M, Al-Jumaili S, Holford K, et al Localisation and identification of fatigue matrix cracking and delamination in a carbon fibre panel by acoustic emission. Compos Part B Eng 2015;74:1-12. http://dx.doi.org/10.1016/j.compositesb.2014.12.032.

[45] Arumugam V, Adhithya A, Sidharth Plato, Santulli C. Characterization of failure modes in compression-after impact of glass-epoxy composite laminates using acoustic emission monitoring. J Braz Soc Mech Sci Eng 2015;37: 1445-55. http://dx.doi.org/10.1007/s40430-014-0263-7.

[46] Sarasini F, Tirillò J, Valente M, Valente T, Cioffi S, Iannace S, et al. Effect of basalt fiber hybridization on the impact behavior under low impact velocity of glass/ basalt woven fabric/epoxy resin composites. Compos Part A Appl Sci Manuf 2013;47:109-23. http://dx.doi.org/10.1016/i.compositesa.2012.11.021.

[47] Huguet S, Godin N, Gaertner R, Salmon L, Villard D. Use of acoustic emission to identify damage modes in glass fibre reinforced polyester. Compos Sci Technol 2002;62:1433-44. http://dx.doi.org/10.1016/S0266-3538(02)00087-8.

[48] Sarasini F, Tirillò J, Ferrante L, Valente M, Valente T, Lampani L, et al. Dropweight impact behaviour of woven hybrid basalt-carbon/epoxy composites. Compos Part B Eng 2014;59:204-20. http://dx.doi.org/10.1016 j.compositesb.2013.12.006. 